\title{
The Use of CD44 Variant 9 and Ki-67 Combination Can Predicts Prognosis Better Than Their Single Use in Early Gastric Cancer
}

\author{
Se-II Go, MD \\ Gyung Hyuck Ko, MD, PhD² \\ Won Sup Lee, MD, PhD ${ }^{3}$ \\ Jeong-Hee Lee, MD, PhD² \\ Sang-Ho Jeong, MD, $\mathrm{PhD}^{4}$ \\ Young-Joon Lee, MD, PhD \\ Soon Chan Hong, MD, PhD \\ Woo Song Ha, MD, PhD ${ }^{5}$
}

\begin{abstract}
${ }^{1}$ Department of Internal Medicine, Institute of Health Sciences, Gyeongsang National University Changwon Hospital, Gyeongsang National University School of Medicine, Changwon, Departments of ${ }^{2}$ Pathology and ${ }^{3}$ Internal Medicine, Institute of Health Sciences, Gyeongsang National University Hospital, Gyeongsang National University School of Medicine, Jinju, ${ }^{4}$ Department of Surgery, Institute of Health Sciences, Gyeongsang National University Changwon Hospital, Gyeongsang National University School of Medicine, Changwon, ${ }^{5}$ Department of Surgery, Institute of Health Sciences, Gyeongsang National University Hospital, Gyeongsang National University School of Medicine, Jinju, Korea
\end{abstract}

\section{Purpose}

We previously demonstrated that CD44v9 and Ki-67 played an important role in predicting poor prognosis of early gastric cancer (EGC). However, little is known about combined use of both biomarkers as prognostic biomarker. The present study was performed to investigate the significance of CD44v9 and Ki-67 expression as a combination biomarker for EGC.

\section{Materials and Methods}

With tissue microarray for 158 EGC tissues, we performed immunohistochemical staining for CD44v9 and Ki-67. The whole patients were divided into three groups (group A, CD44v9negative/Ki-67-low; group B, neither group A or C; and group C, CD44v9-positive/Ki-67high). Its clinical significance was re-analyzed with adjustment via propensity score matching (PSM). For validation, we performed bootstrap resampling.

\section{Results}

The median follow-up duration was 90.4 months (range, 3.7 to 120.4 months). In the comparison according to CD44V9/Ki-67 expression, the combined use of the two biomarker clearly separated the three groups by 5-year survival rates (5-YSR, 96.3\%, 89.8\%, and 76.8\% in group $A, B$, and $C$, respectively; $p=0.009$ ). After PSM, 5-YSR were $97.7 \%$ and $76.8 \%$ in group $A+B$ and group $C$, respectively $(p=0.002)$. Multivariable analysis demonstrated that group $C$ had independently poor prognosis (hazard ratio, 9.137; 95\% confidence interval, 1.187 to $70.366 ; p=0.034$ ) compared with group $A$. Bootstrap resampling internally validated this result $(p=0.016)$.

\section{Conclusion}

This study suggests that both positive CD44v9 and high Ki-67 expression are associated with poor prognosis in EGC, and the combined use of these markers provides better prognostic stratification than the single use of them.

\section{Key words}

CD44v9 antigen, Ki-67 antigen, Stomach neoplasm, Prognosis
Correspondence: Won Sup Lee, MD, PhD Department of Internal Medicine, Institute of Health Sciences, Gyeongsang National University Hospital, Gyeongsang National University School of Medicine, 79 Gangnam-ro, Jinju 52727, Korea

Tel: 82-55-750-8733

Fax: 82-55-758-9122

E-mail:1wshmo@hanmail.net

Received November 30, 2018

Accepted February 23, 2019

Published Online February 25, 2019

*Se-Il Go and Gyung Hyuck Ko contributed equally to this work. 


\section{Introduction}

Notably, gastric cancer (GC) is the third leading cause of cancer-related death worldwide [1] and the second cause of cancer-related death in Korea [2,3]. Histologically, GC has various histologic subtypes and heterogeneity. The cancer heterogeneity can be an obstacle in finding out biomarkers because of its large subgroup where the biomarker does not play a role in predicting prognosis or treatment response, which diminished the effect size [4,5]. Till now, pathologic TNM stage has been still serving as one of the best prognostic markers for GC. However, it is well-known that the prognosis varies in early GC (EGC); some of EGCs shows distant metastasis right after radical resection. Therefore, finding out a new biomarker is essential to predict prognosis of the GC even in EGC.

Recently, we have reported that CD44 variant 9 (CD44v9) and Ki-67 expression can serve as prognostic biomarkers in EGC [4,5]. CD44v9, a variant major adhesion molecule for the extracellular matrix (a surface receptor for hyaluronic acid) [6] is highly expressed at stem cells in mouse gastric tumors [7], and abundantly expressed in epithelial-type carcinomas [8]. It has been implicated in cancer cell adhesion [9], migration [10], and metastasis [11]. In addition, CD44v9 is associated with resistance to chemotherapy or radiotherapy [8] by increasing reduced glutathione through activating cystine-glutamate exchange transporter [12]. Ki-67 protein is widely used as a biomarker for proliferation to determine benign, and malignant tumor, or histologic grade for malignancy [13]. The expression increases in dividing cells and reaches its peak in $\mathrm{M}$ phase [14], so the percentage of $\mathrm{Ki}-67-$ expressing cells (Ki-67 labeling index) has been used as a standard procedure to assess the proliferative activity of neoplastic cells $[15,16]$. In our previous study, each of the proteins (CD44v9 and Ki-67) played an important role in predicting poor prognosis of EGC [4,5]. However, in terms of biological aspects for cancer, the functions of the two proteins are different. CD44v9 is associated with stemness, metastasis, and drug resistance [17-21], while Ki-67 is proliferation and invasion [4,22]. We hypothesized that synergism is expected when the two biomarkers reflecting different activities are used together. In addition, little is known about whether the combined use of the two biomarkers together help to predict better prognosis of EGC than the single biomarker. Therefore, we conducted this study to determine whether the combined use of CD44v9 and Ki-67 expression serves as a better prognostic biomarker in EGC than does the use of single one, either CD44v9 or Ki-67 expression.

\section{Materials and Methods}

\section{Clinical specimens and patients}

Tissue microarray samples were used; they contained 158 EGC and 162 advanced GC (AGC) tissues from the patients with GC who had received radical gastric resection from 1999 to 2007 . Tissue microarray samples were made as previously described [5]. Each tissue core contained the invasive front of GC.

\section{Immunohistochemical staining}

Immunohistochemical (IHC) staining was performed as previously described [4,5]. Briefly, a 4- $\mu$ m-thick paraffinembedded tissue microarray on each slide was treated for epitope retrieval. The primary monoclonal antibodies specific to CD44v9 (kindly provided by Dr. Hideyuki Saya, diluted 1:10,000 to $0.1 \mu \mathrm{g} / \mathrm{mL}$; Keio University School of Medicine, Tokyo, Japan), and Ki-67 (1:2,000, DAKO, Tokyo, Japan) were used. 3,3'-Diaminobenzidine was used for color development and counterstained with hematoxylin. The IHC staining was performed by an automatic staining machine (BenchMark XT, Ventana, Tucson, AZ).

Antigen expression was scored by pathologists with the following guideline and blindness to the clinical data of the patients. The representative figures of CD44v9 and Ki-67 IHC staining are shown in S1 Fig. For CD44v9, the staining intensity was considered as negative when less than $5 \%$ of tumor cells were stained, and positive when $5 \%$ of tumor cells or more were stained. For Ki-67, various cut-off values have been proposed in previous studies for GC ranging from $1 \%$ to $53 \%$ [22]. Because there is no established cut-off value for $\mathrm{Ki}-67$, we used our previous definition that the staining intensity was interpreted as low when less than $20 \%$ of tumor cells were stained, and high when $20 \%$ of tumor cells or more were stained [4]. The whole patients were divided into three groups according to CD44v9 and Ki-67 expression for analysis (group A, CD44v9-negative/Ki-67-low; group B, neither group A or C; and group C, CD44v9-positive/Ki-67-high). Histological type and tumor stage were classified according to the World Health Organization (WHO) [23] and Lauren classification [24], and the 8th edition of American Joint Committee on Cancer TNM system [25], respectively.

\section{Statistical analysis}

All statistical analyses were performed by STATA ver. 14.0 software (College Station, TX) and R ver. 3.4 software ( $R$ Foundation for Statistical Computing, Vienna, Austria). A two-sided $\mathrm{p}$-value of $<0.05$ was considered statistically sig- 
Table 1. Baseline characteristics of early gastric cancer patients

\begin{tabular}{|c|c|c|c|c|}
\hline Characteristic & $\begin{array}{c}\text { Group A } \\
(n=32)\end{array}$ & $\begin{array}{c}\text { Group B } \\
(n=73)\end{array}$ & $\begin{array}{c}\text { Group C } \\
(n=53)\end{array}$ & p-value \\
\hline Age (yr) & $61(35-78)$ & $65(32-78)$ & $66(26-85)$ & 0.183 \\
\hline \multicolumn{5}{|l|}{ Sex } \\
\hline Male & $24(75.0)$ & $48(65.8)$ & $29(54.7)$ & 0.054 \\
\hline Female & $8(25.0)$ & $25(34.3)$ & $24(45.3)$ & \\
\hline \multicolumn{5}{|l|}{ Location } \\
\hline Upper & $2(6.3)$ & $5(6.9)$ & $3(5.7)$ & 0.470 \\
\hline Middle & $8(25.0)$ & $18(24.7)$ & $10(18.9)$ & \\
\hline Lower & $22(68.8)$ & $50(68.5)$ & $40(75.5)$ & \\
\hline \multicolumn{5}{|l|}{ Operation } \\
\hline Subtotal gastrectomy & $25(78.1)$ & $58(79.5)$ & $46(86.8)$ & 0.276 \\
\hline Total gastrectomy & $4(12.5)$ & $11(15.1)$ & $4(7.6)$ & \\
\hline Proximal gastrectomy & $2(6.3)$ & $4(5.5)$ & $2(3.8)$ & \\
\hline Wedge resection & $1(3.1)$ & 0 & $1(1.9)$ & \\
\hline \multicolumn{5}{|l|}{ No. of lymph nodes dissection } \\
\hline$<15$ & $8(25.0)$ & $13(17.8)$ & $15(28.3)$ & 0.561 \\
\hline$\geq 15$ & $24(75.0)$ & $60(82.2)$ & $38(71.7)$ & \\
\hline \multicolumn{5}{|l|}{ Regional lymph node metastasis } \\
\hline Negative & $30(93.8)$ & $65(89.0)$ & $47(88.7)$ & 0.495 \\
\hline Positive & $2(6.3)$ & $8(11.0)$ & $6(11.3)$ & \\
\hline \multicolumn{5}{|l|}{ TNM stage } \\
\hline I & $31(96.9)$ & $72(98.6)$ & $50(94.3)$ & 0.402 \\
\hline II & $1(3.1)$ & $1(1.4)$ & $3(5.7)$ & \\
\hline Tumor size (cm) & $2.2(1.0-5.5)$ & $2.5(1.0-11.0)$ & $2.5(0.5-7.0)$ & 0.354 \\
\hline \multicolumn{5}{|l|}{ WHO classification } \\
\hline Well-differentiated & $8(25.0)$ & $20(27.4)$ & $21(39.6)$ & 0.004 \\
\hline Moderately-differentiated & $7(21.9)$ & $24(32.9)$ & $22(41.5)$ & \\
\hline Poorly-differentiated and others ${ }^{a)}$ & $17(53.1)$ & $29(39.7)$ & $10(18.9)$ & \\
\hline \multicolumn{5}{|l|}{ Lauren classification } \\
\hline Intestinal & $20(62.5)$ & $56(76.7)$ & $47(88.7)$ & 0.007 \\
\hline Diffuse & $10(31.3)$ & $15(20.6)$ & $3(5.7)$ & \\
\hline Mixed & $2(6.3)$ & $2(2.7)$ & $3(5.7)$ & \\
\hline
\end{tabular}

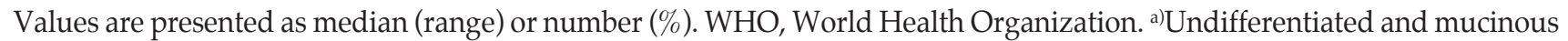
adenocarcinoma, and signet-ring cell carcinoma were included.

nificant. For categorical variables, chi-square, chi-square for trend, and Fisher exact tests were used and Mann-Whitney $\mathrm{U}$ and Kruskal-Wallis tests for continuous variables. The overall survival (OS) was defined as the time from surgery to death of any cause or last follow-up. Kaplan-Meier method was used for survival plot and the difference was analyzed by log-rank test. To identify independent prognostic factors, we used Cox regression model, where all the variables moderately associated with survival $(p<0.10)$ in the univariate analyses were included. The final Cox model was internally validated by bootstrap resampling (1,000 replications). To compare the discriminatory power between CD44v9/Ki-67 and either CD44v9 or Ki-67 alone, the c-indices of each Cox model including these markers were calculated. A c-index of 0.5 indicates random prediction, while a c-index of 1.0 means perfect predictability. Additionally, we performed propensity score matching (PSM) between group $\mathrm{A}+\mathrm{B}$ and group $\mathrm{C}$ to reduce selection bias. Age, sex, and potential predictors for CD44v9 / Ki-67 expression having $\mathrm{p}<0.05$ were included in PSM.

\section{Ethical statement}

Authors were permitted to use these samples for this study by Institutional Review Board of Gyeongsang National University Hospital (GNUHIRB-2009-19), which waived the 
A
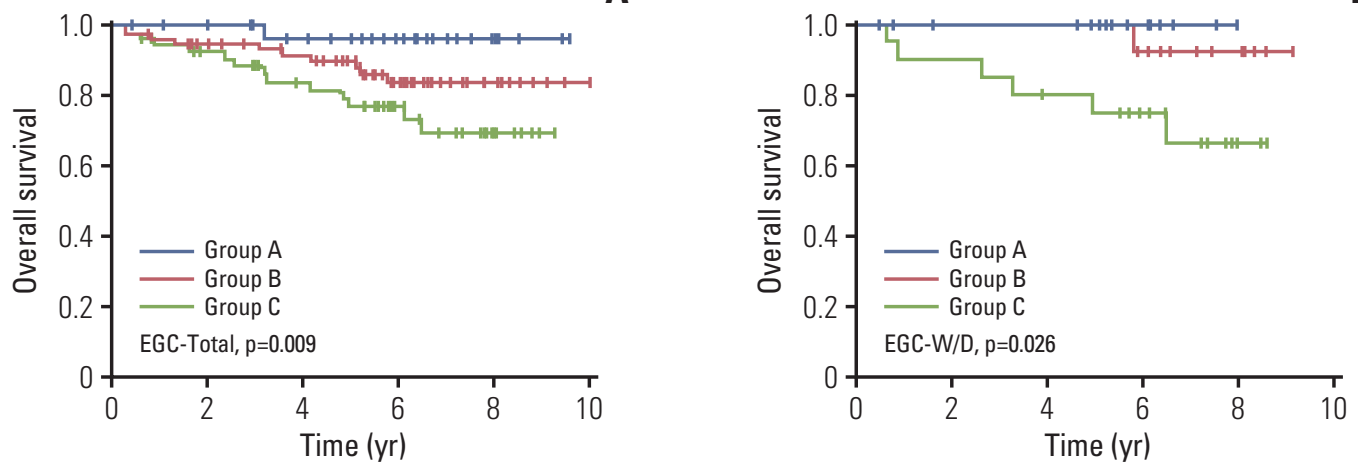

B

C
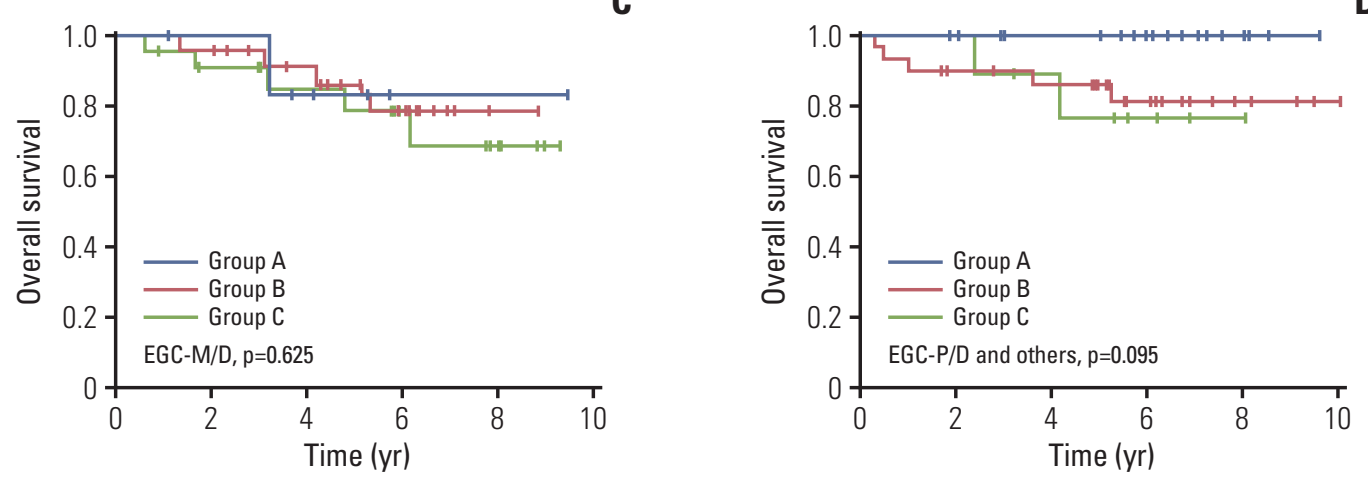

$\mathbf{E}$
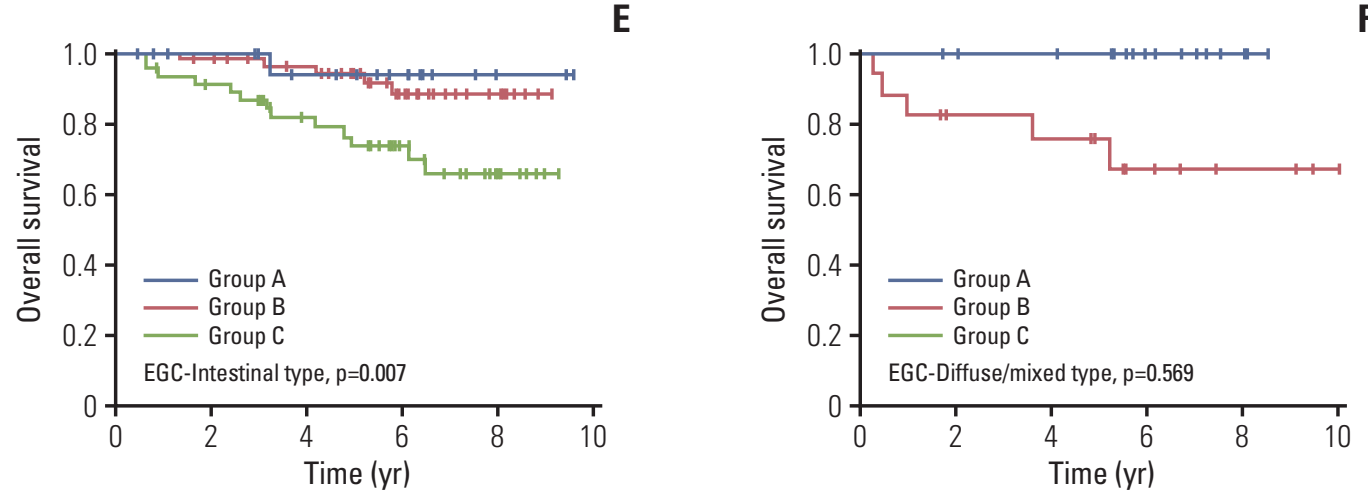

Fig. 1. Kaplan-Meier curves for overall survival according to CD44v9 and Ki-67 expression in early gastric cancer (EGC) patients. (A) Total. (B) Well-differentiated (W/D). (C) Moderately-differentiated (M/D). (D) Poorly-differentiated (P/D) and others. (E) Intestinal type. (F) Diffuse/mixed type. Others indicate undifferentiated and mucinous adenocarcinoma, and signet ring cell carcinoma.

requirement for informed consent because of the retrospective nature of the study.

\section{Results}

\section{Baseline characteristics of EGC patients}

Baseline characteristics of 158 EGC patients are presented in Table 1, showing that the median age at the time of surgery was 65 years (range, 26 to 85 years) with a male pre- 
Table 2. Baseline characteristics of early gastric cancer patients after propensity score matching (PSM)

\begin{tabular}{|c|c|c|c|c|c|}
\hline & $\begin{array}{c}\text { Group A+B } \\
\text { (before PSM) } \\
(\mathrm{n}=105)\end{array}$ & $\begin{array}{c}\text { Group A+B } \\
\text { (after PSM) } \\
(\mathrm{n}=53)\end{array}$ & $\begin{array}{c}\text { Group C } \\
(n=53)\end{array}$ & $\begin{array}{c}\text { p-value (group } \\
\text { A+B vs. C } \\
\text { before PSM) }\end{array}$ & $\begin{array}{c}\text { p-value (group } \\
\text { A+B vs. C } \\
\text { after PSM) }\end{array}$ \\
\hline Age $(\mathrm{yr})$ & $64(32-78)$ & $67(32-77)$ & $66(26-85)$ & 0.133 & 0.613 \\
\hline \multicolumn{6}{|l|}{ Sex } \\
\hline Male & $72(68.6)$ & $32(60.4)$ & $29(54.7)$ & 0.087 & 0.556 \\
\hline Female & $33(31.4)$ & $21(39.6)$ & $24(45.3)$ & & \\
\hline \multicolumn{6}{|l|}{ Location } \\
\hline Upper & $7(6.7)$ & $2(3.8)$ & $3(5.7)$ & 0.660 & 0.821 \\
\hline Middle & $26(24.8)$ & $12(22.6)$ & $10(18.9)$ & & \\
\hline Lower & $72(68.6)$ & $39(73.6)$ & $40(75.5)$ & & \\
\hline \multicolumn{6}{|l|}{ Operation } \\
\hline Subtotal gastrectomy & $83(79.1)$ & $42(79.3)$ & $46(86.8)$ & 0.553 & 0.753 \\
\hline Total gastrectomy & $15(14.3)$ & $7(13.2)$ & $4(7.6)$ & & \\
\hline Proximal gastrectomy & $6(5.7)$ & $3(5.7)$ & $2(3.8)$ & & \\
\hline Wedge resection & $1(1.0)$ & $1(1.9)$ & $1(1.9)$ & & \\
\hline \multicolumn{6}{|l|}{ No. of lymph nodes dissection } \\
\hline$<15$ & $21(20.0)$ & $12(22.6)$ & $15(28.3)$ & 0.240 & 0.504 \\
\hline$\geq 15$ & $84(80.0)$ & $41(77.4)$ & $38(71.7)$ & & \\
\hline \multicolumn{6}{|l|}{ Regional lymph node metastasis } \\
\hline Negative & $95(90.5)$ & $47(88.7)$ & $47(88.7)$ & 0.724 & $>0.990$ \\
\hline Positive & $10(9.5)$ & $6(11.3)$ & $6(11.3)$ & & \\
\hline \multicolumn{6}{|l|}{ TNM stage } \\
\hline I & $103(98.1)$ & $52(98.1)$ & $50(94.3)$ & 0.335 & 0.618 \\
\hline II & $2(1.9)$ & $1(1.9)$ & $3(5.7)$ & & \\
\hline Tumor size (cm) & $2.5(1.0-11.0)$ & $2.5(1.0-11.0)$ & $2.5(0.5-7.0)$ & 0.368 & 0.484 \\
\hline \multicolumn{6}{|l|}{ WHO classification } \\
\hline Well-differentiated & $28(26.7)$ & $25(47.2)$ & $21(39.6)$ & 0.008 & 0.478 \\
\hline Moderately-differentiated & $31(29.5)$ & $16(30.2)$ & $22(41.5)$ & & \\
\hline Poorly-differentiated and others ${ }^{\mathrm{a})}$ & $46(43.8)$ & $12(22.6)$ & $10(18.9)$ & & \\
\hline \multicolumn{6}{|l|}{ Lauren classification } \\
\hline Intestinal & $76(72.4)$ & $47(88.7)$ & $47(88.7)$ & 0.018 & 0.472 \\
\hline Diffuse & $25(23.8)$ & $5(9.4)$ & $3(5.7)$ & & \\
\hline Mixed & $4(3.8)$ & $1(1.9)$ & $3(5.7)$ & & \\
\hline
\end{tabular}

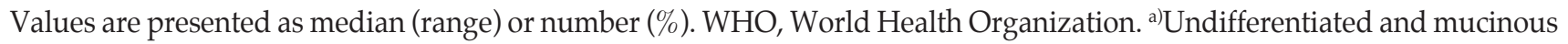
adenocarcinoma, and signet-ring cell carcinoma were included.

dominance ( $\mathrm{n}=101,63.9 \%)$. The most frequently performed surgery was subtotal gastrectomy $(\mathrm{n}=129,81.7 \%)$. Fifteen lymph node or more were excised in 122 patients (77.2\%). All but five patients $(96.8 \%)$ had stage I disease. The histologic grade according to the WHO classification was evenly distributed, whereas the intestinal-type $(\mathrm{n}=123,77.9 \%)$ was observed to be predominant according to the Lauren classification. No significant differences between groups have been observed in demographics, surgery type, location, lymph node metastasis, stage, and tumor size. However, the histologic subtypes known to be associated with better prognosis in GC (well-differentiated [W/D] histology and intes- tinal type) were more frequently distributed in the following order of groups $\mathrm{C}, \mathrm{B}$, and $\mathrm{A}$ (WHO classification, $\mathrm{p}=0.004$; Lauren classification, $\mathrm{p}=0.007$ ).

\section{The role of CD44v9/Ki-67 as a prognostic biomarker in EGC}

The median follow-up duration was 90.4 months (range, 3.7 to 120.4 months). In all EGC patients, 5-year survival rate (5-YSR) was $86.7 \%$ (95\% confidence interval [CI], 79.8 to 91.3). Based on CD44v9/ Ki-67 expression, 5 -YSR were $96.3 \%$, $89.8 \%$, and $76.8 \%$ in group $\mathrm{A}, \mathrm{B}$, and $\mathrm{C}$, respectively $(\mathrm{p}=0.009)$ 


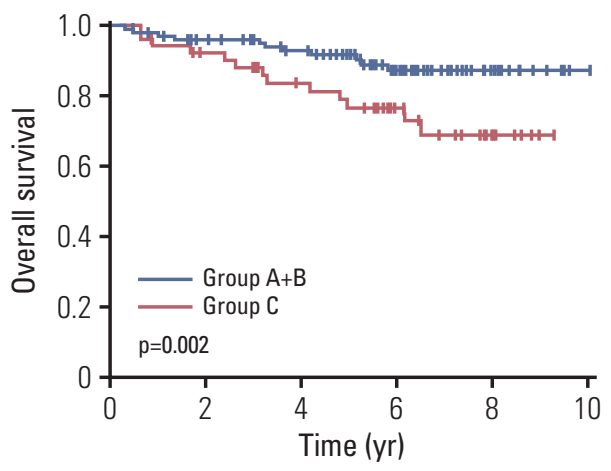

Fig. 2. Kaplan-Meier curves for overall survival according to CD44v9 and Ki-67 expression in early gastric cancer after propensity score matching.

(Fig. 1A). In subgroup analyses, it was found that CD44v9/ $\mathrm{Ki}-67$ expression played a role in predicting prognosis in $\mathrm{W} / \mathrm{D}$ histology of EGC ( $\mathrm{p}=0.026)$, but not in other moderately-differentiated $(\mathrm{M} / \mathrm{D})$ and poorly-differentiated $(\mathrm{P} / \mathrm{D})$ histology of EGC ( $\mathrm{p}=0.625$ and $\mathrm{p}=0.095$, respectively) (Fig. 1B-D). When CD44-v9/ Ki-67 served as a prognostic fac- tor in intestinal type of EGC ( $\mathrm{p}=0.007)$ (Fig. 1E), but not in diffuse/mixed type ( $\mathrm{p}=0.569)$ (Fig. 1F). After PSM between group $A+B$ and group $C(n=106)$, there were no longer significant differences in the patients' characteristics (Table 2, S2 Fig.). The 5-YSR adjusted with PSM were $97.7 \%$ and 76.8\% in group $\mathrm{A}+\mathrm{B}$ and group $\mathrm{C}$, respectively ( $\mathrm{p}=0.002$ ) (Fig. 2).

On univariate analyses, age $\geq 65$, male sex, upper third location, lymph node metastasis, and group $C$ were detected as potential poor prognostic factors for OS. Among them, male sex (hazard ratio [HR], 3.465; 95\% CI, 1.135 to 10.584; $\mathrm{p}=0.029)$ and group $\mathrm{C}(\mathrm{HR}, 9.137 ; 95 \% \mathrm{CI}, 1.187$ to 70.366 ; $\mathrm{p}=0.034$ ) were independent prognostic factors for OS. Bootstrap resampling internally validated this result $(\mathrm{p}=0.016)$ (Table 3). The c-indices of multivariate Cox regression models including CD44v9/Ki-67, CD44v9, and Ki-67 variables were 0.75 (95\% CI, 0.67 to 0.83 ), 0.71 (95\% CI, 0.61 to 0.81 ), and 0.72 (95\% CI, 0.63 to 0.81 ), respectively. These findings suggest that combined use of both the biomarkers (CD44v9/ Ki-67) serves better as a prognostic biomarker for EGC than the use of single biomarker, that is- either CD44v9 or Ki-67.

Table 3. Cox regression for overall survival in early gastric cancer patients

\begin{tabular}{|c|c|c|c|c|c|c|c|}
\hline & \multicolumn{3}{|c|}{ Univariate } & \multicolumn{4}{|c|}{ Multivariate } \\
\hline & HR & $95 \% \mathrm{CI}$ & p-value & HR & $95 \% \mathrm{CI}$ & p-value & $\begin{array}{l}\text { p-value } \\
\text { (bootstrap) }\end{array}$ \\
\hline Age $(\geq 65$ yr vs. $<65$ yr) & 2.178 & $0.932-5.092$ & 0.072 & 1.913 & $0.794-4.607$ & 0.148 & 0.153 \\
\hline Sex (male vs. female) & 2.751 & $0.940-8.049$ & 0.065 & 3.465 & $1.135-10.584$ & 0.029 & 0.019 \\
\hline Location (upper vs. middle/lower) & 2.999 & $1.023-8.793$ & 0.045 & 1.560 & $0.461-5.274$ & 0.475 & 0.540 \\
\hline Operation (subtotal gastrectomy vs. others) & 1.164 & $0.435-3.119$ & 0.762 & - & - & - & - \\
\hline No. of lymph nodes dissection (<15 vs. $\geq 15$ ) & 1.814 & $0.776-4.243$ & 0.169 & - & - & - & - \\
\hline $\begin{array}{l}\text { Regional lymph node metastasis } \\
\text { (negative vs. positive) }\end{array}$ & 2.962 & $1.004-8.744$ & 0.049 & 2.609 & $0.744-9.143$ & 0.134 & 0.183 \\
\hline Tumor size $(\geq 4 \mathrm{~cm}$ vs. $<4 \mathrm{~cm})$ & 0.605 & $0.226-1.620$ & 0.317 & - & - & - & - \\
\hline \multicolumn{8}{|l|}{ WHO classification } \\
\hline Well-differentiated & Reference & & & & & & \\
\hline Moderately-differentiated & 1.547 & $0.587-4.075$ & 0.377 & - & - & - & - \\
\hline Poorly-differentiated and others ${ }^{\text {a) }}$ & 0.923 & $0.324-2.633$ & 0.881 & - & - & - & - \\
\hline $\begin{array}{l}\text { Lauren classification } \\
\text { (diffuse/mixed vs. intestinal) }\end{array}$ & 0.920 & $0.344-2.465$ & 0.869 & - & - & - & - \\
\hline \multicolumn{8}{|l|}{ CD44v9 and Ki-67 } \\
\hline Group A & Reference & & & Reference & & & \\
\hline Group B & 4.510 & $0.577-35.232$ & 0.151 & 4.070 & $0.515-32.194$ & 0.183 & 0.092 \\
\hline Group C & 8.475 & $1.109-64.795$ & 0.039 & 9.137 & $1.187-70.366$ & 0.034 & 0.016 \\
\hline
\end{tabular}

HR, hazard ratio; CI, confidence interval; WHO, World Health Organization. a)Undifferentiated and mucinous adenocarcinoma, and signet-ring cell carcinoma were included. 
A

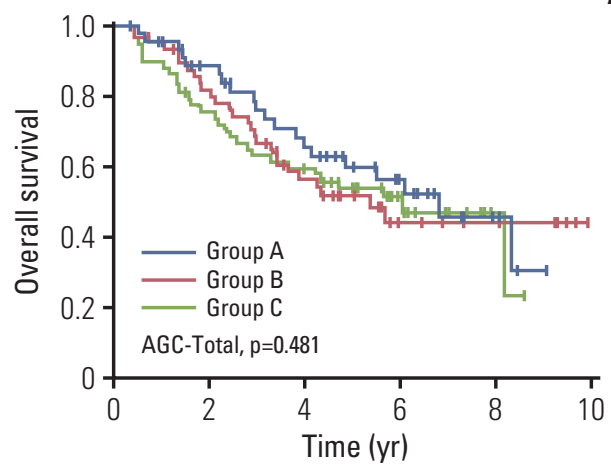

C

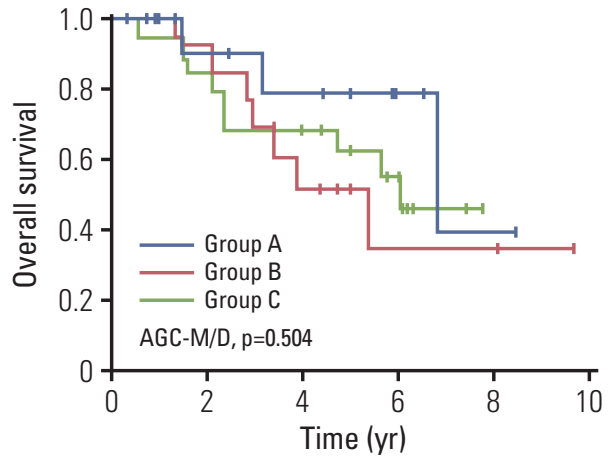

$\mathbf{E}$

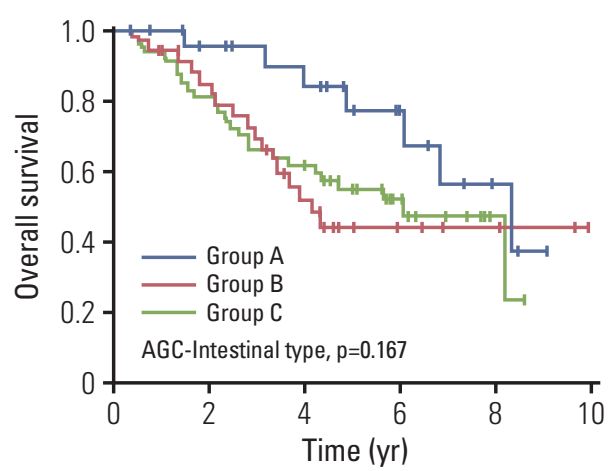

B

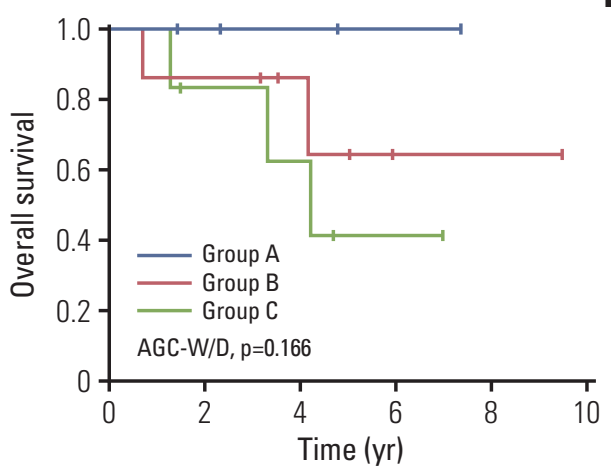

D

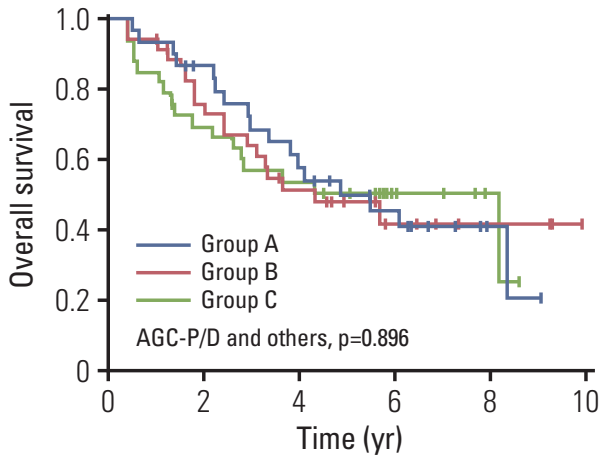

$\mathbf{F}$

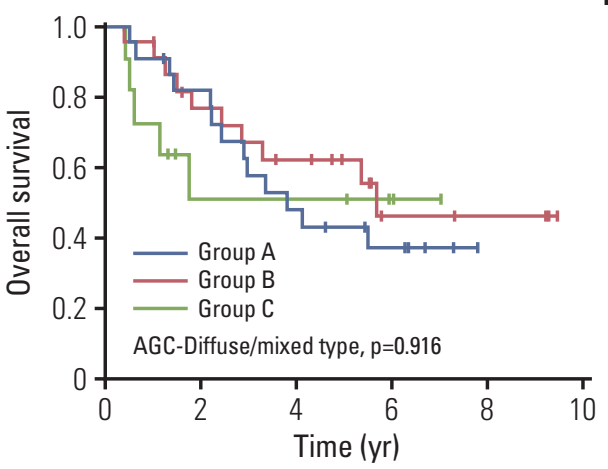

Fig. 3. Kaplan-Meier curves for overall survival according to CD44v9 and Ki-67 expression in advanced gastric cancer (AGC) patients. (A) Total. (B) Well-differentiated (W/D). (C) Moderately-differentiated (M/D). (D) Poorly-differentiated (P/D) and others. (E) Intestinal type. (F) Diffuse/mixed type. Others indicate undifferentiated and mucinous adenocarcinoma, and signet ring cell carcinoma.

\section{The role of $\mathrm{CD} 44 \mathrm{v} 9 / \mathrm{Ki}-67$ as a prognostic biomarker in AGC}

Next, we assessed the role of CD44v9/Ki-67 in AGC patients $(n=162)$. There were no differences in baseline characteristics except age and Lauren classification (S3 Table). It was revealed that CD44v9/ Ki-67 did not serve as a prognostic factor in this population ( $\mathrm{p}=0.481$ ) (Fig. $3 \mathrm{~A}$ ). In subgroup analyses, it was found that $\mathrm{CD} 44 \mathrm{v} 9 / \mathrm{Ki}-67$ expression did not serve as a prognostic factor in $\mathrm{W} / \mathrm{D}$ histology $(\mathrm{p}=0.166)$ as well as in $\mathrm{M} / \mathrm{D}$ and $\mathrm{P} / \mathrm{D}$ histology $(\mathrm{p}=0.504$ and $\mathrm{p}=0.896$, respectively) (Fig. 3B-D). Similarly, there was no prognostic value of CD44v9/Ki-67 expression in AGC regardless of Lauren classification (Fig. 3E and F). These findings support that CD44v9/Ki-67 played an important role in predicting prognosis in EGC, but not in AGC. 


\section{Discussion}

This study was designed to determine whether the two biomarkers, CD44v9 and Ki-67 serve better as a prognostic factor in EGC than either any one of them. Hence, we compared survivals among the three groups (negative/low, negative/high or positive/low, and positive/high for CD44v9 and Ki-67 expression) in EGC. It was found that the groups of both up-regulated expression of CD44v9 and Ki-67 showed the worst survival results among the three groups, and validated the results with bootstrap resampling.

The prognosis of cancer is largely determined by cancer metastasis. Metastasis is determined by the activity of various factors such as tumor growth, tissue adhesion, neovascularization, immune evasion, and drug resistance. Aggressiveness of tumor is always challenging and could be represented by the rapid tumor cell proliferation and metastasis capability in cancer. In search of biomarkers for the aggressiveness or metastasis, it has been reported that CD $44 \mathrm{v} 9$ serves as stem cell, and metastasis biomarker [17-21], and Ki-67 represents as proliferation and invasion biomarker $[4,14,22]$. Therefore, the use of a biomarker to evaluate each of these factors can be more accurate in assessing the prognosis than using a biomarker with a monopoly. The synergism is expected when the two biomarkers reflecting different activities are used together for prognosis. This assumption was confirmed in this study by showing that the EGC expressing both high Ki-67 (proliferation biomarker) and positive CD44v9 (stem cell, and metastasis biomarker) are with the worst outcome and that the Cox regression model including CD44v9/Ki-67 expression showed a higher discriminating ability for survival compared with those including either CD44v9 or Ki-67 expression alone. In addition, multigene assays have been widely used as a guideline for adjuvant chemotherapy for early breast cancer treatment $[26,27]$. This study also confirm that the combined use of two biomarkers serves as a significant prognostic factors only in EGC but not in AGC although the combined use better predicts prognosis of GC than single use.

The limitation in this investigation is that we could not clearly demonstrate the difference in role of CD44v9 and $\mathrm{Ki}-67$ combination as a prognostic biomarker in $\mathrm{M} / \mathrm{D}$, and $\mathrm{P} / \mathrm{D}$ histologic subtype of EGC, which is presume to be due to the small sample size. Previous studies reported that Ki-67 tended to better reflect the prognosis in the W/D histologic type of EGC [4]. Moreover, histological observation studies have revealed that, $\mathrm{W} / \mathrm{D}$ type is predominant in EGC of the elderly, while in AGC, predominant is mixed type which is composed of $W / D$ type in the superficial area, and $\mathrm{P} / \mathrm{D}$ type in the deeper area $[28,29]$. These findings suggest that majority of intestinal type of AGCs are principally W/D adenocarcinomas which have progressed to $\mathrm{P} / \mathrm{D}$ adenocarcinomas as EGC progress to AGC. Taking into account this fact, $\mathrm{M} / \mathrm{D}$ and $\mathrm{P} / \mathrm{D}$ histological subtype could be more heterogeneous than $\mathrm{W} / \mathrm{D}$ type. In this context, there is a possibility that CD44v9 and Ki-67 combination serves less as a prognostic biomarker in $\mathrm{M} / \mathrm{D}$, and $\mathrm{P} / \mathrm{D}$ histologic subtype of EGC than in W/D histologic subtype of EGC. Therefore, further larger research is warranted at this point.

The merit of this study is that we have applied two biomarkers with different function at the same staged cancer, which is making it more chance to avoid heterogeneity. Previous many studies investigated role of each of the biomarkers Ki-67, standard or variant of CD44 in the EGC or for whole GC group including AGC [4,5,30-32]. In these studies, the results in EGC was clear than the others. Secondly, we had performed propensity-score matching analysis, and validated the final results with bootstrap resampling to eliminate hidden biases. The last point to emphasize is that this study indicated that the prognosis of the patients with cancer expressing both positive CD44v9 and high Ki-67 was as poor as those with AGC, which suggests that these patients need further treatment to reduce relapse of GC.

In conclusion, these results suggest that both positive CD44v9 and high Ki-67 expression are associated with poor prognosis in EGC, and the combined use of these markers provides better prognostic stratification than the single use of them.

\section{Electronic Supplementary Material}

Supplementary materials are available at Cancer Research and Treatment website (https:// www.e-crt.org).

\section{Conflicts of Interest}

Conflict of interest relevant to this article was not reported.

\section{Acknowledgments}

This study was supported by a grant of the National R\&D Program for Cancer Control, Ministry for Health, Welfare and Family Affairs, Republic of Korea (0820050), in part by a grant from the Korean Cancer Research Institute. We really appreciate Dr. Suchismita Raha's advice and English editing in writing the manuscripts. 


\section{References}

1. Siegel RL, Miller KD, Jemal A. Cancer statistics, 2016. CA Cancer J Clin. 2016;66:7-30.

2. Song HN, Go SI, Lee WS, Kim Y, Choi HJ, Lee US, et al. Population-based regional cancer incidence in Korea: comparison between urban and rural areas. Cancer Res Treat. 2016;48:789-97.

3. Oh CM, Won YJ, Jung KW, Kong HJ, Cho H, Lee JK, et al. Cancer statistics in Korea: incidence, mortality, survival, and prevalence in 2013. Cancer Res Treat. 2016;48:436-50.

4. Ko GH, Go SI, Lee WS, Lee JH, Jeong SH, Lee YJ, et al. Prognostic impact of Ki-67 in patients with gastric cancer-the importance of depth of invasion and histologic differentiation. Medicine (Baltimore). 2017;96:e7181.

5. Go SI, Ko GH, Lee WS, Kim RB, Lee JH, Jeong SH, et al. CD44 variant 9 serves as a poor prognostic marker in early gastric cancer, but not in advanced gastric cancer. Cancer Res Treat. 2016;48:142-52.

6. Aruffo A, Stamenkovic I, Melnick M, Underhill CB, Seed B. CD44 is the principal cell surface receptor for hyaluronate. Cell. 1990;61:1303-13.

7. Ishimoto T, Oshima H, Oshima M, Kai K, Torii R, Masuko T, et al. CD44+slow-cycling tumor cell expansion is triggered by cooperative actions of Wnt and prostaglandin E2 in gastric tumorigenesis. Cancer Sci. 2010;101:673-8.

8. Diehn M, Cho RW, Lobo NA, Kalisky T, Dorie MJ, Kulp AN, et al. Association of reactive oxygen species levels and radioresistance in cancer stem cells. Nature. 2009;458:780-3.

9. Culty M, Miyake K, Kincade PW, Sikorski E, Butcher EC, Underhill C. The hyaluronate receptor is a member of the CD44 (H-CAM) family of cell surface glycoproteins. J Cell Biol. 1990;111(6 Pt 1):2765-74.

10. Thomas L, Byers HR, Vink J, Stamenkovic I. CD44H regulates tumor cell migration on hyaluronate-coated substrate. J Cell Biol. 1992;118:971-7.

11. Gunthert U, Hofmann M, Rudy W, Reber S, Zoller M, Haussmann I, et al. A new variant of glycoprotein CD44 confers metastatic potential to rat carcinoma cells. Cell. 1991;65:13-24.

12. Ishimoto T, Nagano $O, Y a e ~ T$, Tamada M, Motohara T, Oshima $\mathrm{H}$, et al. CD44 variant regulates redox status in cancer cells by stabilizing the $\mathrm{xCT}$ subunit of system $\mathrm{xc}(-)$ and thereby promotes tumor growth. Cancer Cell. 2011;19:387-400.

13. Scholzen T, Gerdes J. The Ki-67 protein: from the known and the unknown. J Cell Physiol. 2000;182:311-22.

14. Gerdes J, Lemke H, Baisch H, Wacker HH, Schwab U, Stein H. Cell cycle analysis of a cell proliferation-associated human nuclear antigen defined by the monoclonal antibody Ki-67. J Immunol. 1984;133:1710-5.

15. Deshmukh P, Ramsey L, Garewal HS. Ki-67 labeling index is a more reliable measure of solid tumor proliferative activity than tritiated thymidine labeling. Am J Clin Pathol. 1990;94: 192-5.

16. Cher ML, Chew K, Rosenau W, Carroll PR. Cellular proliferation in prostatic adenocarcinoma as assessed by bromodeoxyuridine uptake and Ki-67 and PCNA expression. Prostate. 1995;26:87-93.

17. Al-Hajj M, Wicha MS, Benito-Hernandez A, Morrison SJ,
Clarke MF. Prospective identification of tumorigenic breast cancer cells. Proc Natl Acad Sci U S A. 2003;100:3983-8.

18. Dalerba P, Dylla SJ, Park IK, Liu R, Wang X, Cho RW, et al. Phenotypic characterization of human colorectal cancer stem cells. Proc Natl Acad Sci U S A. 2007;104:10158-63.

19. Zavros Y. Initiation and maintenance of gastric cancer: a focus on CD44 variant isoforms and cancer stem cells. Cell Mol Gastroenterol Hepatol. 2017;4:55-63.

20. Singh SR. Gastric cancer stem cells: a novel therapeutic target. Cancer Lett. 2013;338:110-9.

21. Kodama H, Murata S, Ishida M, Yamamoto H, Yamaguchi T, Kaida S, et al. Prognostic impact of CD44-positive cancer stemlike cells at the invasive front of gastric cancer. Br J Cancer. 2017;116:186-94.

22. Luo G, Hu Y, Zhang Z, Wang P, Luo Z, Lin J, et al. Clinicopathologic significance and prognostic value of Ki-67 expression in patients with gastric cancer: a meta-analysis. Oncotarget. 2017;8:50273-83.

23. Hu B, El Hajj N, Sittler S, Lammert N, Barnes R, Meloni-Ehrig A. Gastric cancer: classification, histology and application of molecular pathology. J Gastrointest Oncol. 2012;3:251-61.

24. Lauren P. The two histological main types of gastric carcinoma: diffuse and so-called intestinal-type carcinoma: an attempt at a histo-clinical classification. Acta Pathol Microbiol Scand. 1965;64:31-49.

25. Amin MB, Edge S, Greene F, Byrd DR, Brookland RK, Washington MK, et al. AJCC cancer staging manual. 8th ed. New York, NY: Springer; 2016.

26. Jerzak KJ, Pritchard KI. The 21-gene recurrence score assay in node-negative early breast cancer: prognostic, predictive or presumptuous? Eur J Cancer. 2016;68:173-5.

27. Sestak I, Buus R, Cuzick J, Dubsky P, Kronenwett R, Denkert $\mathrm{C}$, et al. Comparison of the performance of 6 prognostic signatures for estrogen receptor-positive breast cancer: a secondary analysis of a randomized clinical trial. JAMA Oncol. 2018;4:545-53.

28. Inoshita N, Yanagisawa A, Arai T, Kitagawa T, Hirokawa K, Kato Y. Pathological characteristics of gastric carcinomas in the very old. Jpn J Cancer Res. 1998;89:1087-92.

29. Arai T, Esaki Y, Inoshita N, Sawabe M, Kasahara I, Kuroiwa $\mathrm{K}$, et al. Pathologic characteristics of gastric cancer in the elderly: a retrospective study of 994 surgical patients. Gastric Cancer. 2004;7:154-9.

30. Hassani Joutei HA, Marchoudi N, Sadaoui I, Mahfoud W, Haddad F, Fechtali T, et al. Ki67 proliferative index in gastric cancer: a useful prognostic marker? Anticancer Res. 2014;34: 5806.

31. Costa L, Fradique AC, Pupo A, Quaresma L, Cabrita F, Da Silva $\mathrm{G}$, et al. Ki 67 showed statistical prognostic significance in intestinal type of gastric cancer. Ann Oncol. 2013;24(Suppl 4):iv59.

32. Fang M, Wu J, Lai X, Ai H, Tao Y, Zhu B, et al. CD44 and CD44v6 are correlated with gastric cancer progression and poor patient prognosis: evidence from 42 studies. Cell Physiol Biochem. 2016;40:567-78. 